\title{
Systematic hydrolysis of PIM-1 and electrospinning of hydrolyzed PIM-1 ultrafine fibers for an efficient removal of dye from water
}

\author{
Bekir Satilmis $^{\mathrm{a}, \mathrm{b}, * *}$, Peter M. Budd ${ }^{\mathrm{c}}$, Tamer Uyar $^{\mathrm{a}}{ }^{\mathrm{a}, *}$ \\ a Institute of Materials Science \& Nanotechnology, UNAM-National Nanotechnology Research Center, Bilkent University, Ankara 06800, Turkey \\ b Department of Chemistry, Faculty of Science and Arts, Ahi Evran University, Kirsehir 40100, Turkey \\ ' School of Chemistry, University of Manchester, Manchester, M13 9PL, UK
}

\section{A R T I C L E I N F O}

\section{Keywords:}

Electrospinning

Hydrolyzed PIM-1

Nanofibers

Dye filtration

Wastewater treatment

\begin{abstract}
A B S T R A C T
In this study, the Polymer of Intrinsic Microporosity (PIM-1) was systematically hydrolyzed in the presence of sodium hydroxide by varying the concentration of base, washing procedure and the time of the reaction. The chemical structure analyses confirmed that PIM-1 could be hydrolyzed by $65 \%$ up to $99 \%$ conversion depending on the synthesis procedure. The hydrolyzed PIM-1 samples have shown improved solubility which facilitates the fabrication of hydrolyzed PIM-1 ultrafine fibers by electrospinning technique. Extensive optimization studies were performed for the electrospinning of uniform and bead-free fibers from hydrolyzed PIM-1 with different degree of hydrolysis $(65 \%, 86 \%, 94 \%$ and $99 \%)$. The electrospun hydrolysed PIM-1 fibrous samples have average fiber diameters (AFD) ranging from $0.58 \pm 0.15 \mu \mathrm{m}$ to $1.21 \pm 0.15 \mu \mathrm{m}$, depending on the polymer concentration and applied electrospinning parameters. After electrospinning, self-standing hydrolyzed PIM-1 fibrous membranes were obtained which is useful as a filtering material for the adsorption of organic dyes from wastewater. Here, the capability of hydrolyzed PIM-1 electrospun fibrous membranes for the removal of dyes from aqueous solutions was investigated by using a batch adsorption process. The maximum adsorption capacity of fully hydrolyzed PIM-1 fibers was found $157 \pm 16 \mathrm{mg} \mathrm{g}^{-1}$ for Methylene Blue and $4 \mathrm{mg} \mathrm{g}^{-1}$ for Congo red when the adsorption was conducted by $20 \mathrm{mg} \mathrm{L}^{-1}$ dye solution without using any dilution. Moreover, maximum dye adsorption was also studied by using concentrated Methylene Blue solutions showing up to $272 \mathrm{mg} \mathrm{g}^{-1}$ adsorption maximum. In addition, the self-standing fibrous hydrolyzed PIM-1 membrane was employed to separate Methylene Blue from an aqueous system by filtration without the necessity of additional driving force. The results indicate that hydrolyzed PIM-1 electrospun nanofibrous membranes can be a promising filtering material for wastewater treatment
\end{abstract}

\section{Introduction}

The consumption of world resources is increasing in correlation with population growth and industrialization. Therefore, new technologies and materials are required to improve the efficiency and effectiveness of industrial processes [1-3]. This includes the removal of organic compounds from aqueous media [4-8], which is important for several applications, such as recovery of biorefinery products, isolation of natural products and wastewater treatment [9-12]. Several methods have been developed to achieve this, including adsorption, centrifugation, precipitation, sedimentation and filtration [13]. Dyes are useful model compounds to assess the uptake of potential sorbents and membrane materials.

Polymers of Intrinsic Microporosity (PIMs) possess rigid and contorted structures that cannot pack space efficiently. Thus, they have high free volume and behave like a molecular basket [14]. PIMs have been investigated as membrane materials [15-17], sensors [18], adsorbents [19] and for other applications [20,21]. Although many PIM polymers have been synthesized, the first member of this class, named PIM-1, has attracted most attention due to its ready synthesis from commercially available monomers. PIM- 1 is soluble in some common organic solvents and hence can be processed into the forms of powders, membranes and fibers [22,23]. PIM-1 has a hydrophobic nature along with a high free volume that makes it an attractive candidate as a porous adsorbent.

Among the available techniques for the preparation of porous adsorbents, electrospinning is a simple, cost effective and versatile method to obtain three-dimensional and self-standing fibrous

\footnotetext{
* Corresponding author.

** Correspondence to: B. Satilmis, Department of Chemistry, Faculty of Science and Arts, Ahi Evran University, Kirsehir 40100, Turkey.

E-mail addresses: bekir.satilmis1@gmail.com (B. Satilmis), uyar@unam.bilkent.edu.tr (T. Uyar).
} 
membranes [24-26]. Electrospinning enables the formation of nanofibers/nanowebs with a nanoscale porosity along with a very high surface area [27]. Electrospun fibers are employed in various applications such as filtration, biomedical, tissue engineering, nanocatalysis, sensors and food, etc. [24-30] On the other hand, electrospinning of PIM-1 is a relatively new concept which was investigated very recently [31-34]. Bonso et al. [31] was successfully prepared electrospun PIM-1 fiber in tetrachloroethane solution which was then carbonized and used as an electrode for supercapacitors. Following this, Lasseuguette et al. [34] proposed another solvent system for the fabrication of electrospun PIM1 by using THF/DMF mixture. Zhang et al. [33] was prepared PIM-1/ POSS fibrous membranes and they have investigated the ability of the membranes in oil-water separation. In addition, the adsorption of dyes from non-aqueous media by electrospun PIM-1 was reported by the same group [32]. However, the hydrophobicity limits the use of PIM-1 in aqueous solutions as it inhibits its interaction ability with waste molecules in water. Tailoring the interaction ability of PIM-1 is possible by modifying the nitrile group in the polymer backbone [35-41]. While hydrolyzed PIMs show high affinity for cationic species, amine and hydroxyalkyaminoalkyamide PIMs exhibit enhanced affinity for anionic species, compared to the parent PIM-1 [42]. Moreover, the water contact angle of PIM- 1 can be reduced from $85^{\circ}$ to $60^{\circ}$ by either amine modification or hydrolysis reaction that may improve the possible use of PIM-1 in aqueous media [35,38]. From this standpoint, Zhang et al. [43] was studied the post-treatment of PIM-1 fiber with base to obtain hydrolyzed PIM-1 fiber. The study has revealed that hydrophilicity of PIM-1 fibers was improved by hydrolysis as well as their dye removal ability towards cationic dyes in aqueous media. However, the hydrolysis procedure of electrospun PIM-1 fibers has caused severe damages to fibers where fibers become fragile and lost their mechanical and structural properties.

In this study, we have reported the optimum conditions to prepare electrospun hydrolyzed PIM-1 fibers. For this purpose, PIM-1 powder was hydrolyzed in the presence of base under different conditions in order to find out the best solubility behavior that enables the electrospinning of hydrolyzed PIM-1 fibers. This method has an advantage over post-treatment method [43] not only it rules out the handling difficulty but also it introduces a novel polymer matrix for the future electrospinning studies. The bead-free, smooth and uniform ultrafine fibers were electrospun from hydrolyzed PIM-1 having different degree of hydrolysis (65\%, 86\%, 94\% and 99\%). The self-standing hydrolysed PIM-1 fibrous membranes were obtained by electrospinning which could be used for filtration purposes. The hydrolysed PIM-1 fibrous membranes have shown enhanced adsorption capacity towards cationic dyes (i.e. Methylene Blue (MB)) and low adsorption capacity against anionic dyes (i.e. Congo Red) in the aqueous system. Moreover, selfstanding, fibrous membrane of hydrolyzed PIM-1 was utilized to separate MB dye from an aqueous system. The desorption of MB was also achieved by using basic alcohol solution which might be the only limitation about electrospun fibrous hydrolyzed PIMs since PIMs swells in the presence of alcohol and it causes slight damage on the physical shape of the membrane.

\section{Experimental}

\subsection{Materials}

5,5',6,6'-Tetrahydroxy-3,3, 3', $3^{\prime}$-tetramethyl-1, $1^{\prime}$-spirobisindane (TTSBI, 98\%, Alfa Aesar) was dissolved in methanol and re-precipitated from dichloromethane before use. Tetrafluoroterephthalonitrile (TFTN, $98 \%$, Aldrich) was purified by sublimation; it was heated to around $150{ }^{\circ} \mathrm{C}$ and the pure product collected without vacuum. Anhydrous potassium carbonate $\left(\mathrm{K}_{2} \mathrm{CO}_{3}, 99.0 \%\right.$, Fisher) was dried in an oven at $110^{\circ} \mathrm{C}$ overnight before use. Dimethylacetamide (DMAc), toluene, dimethylformamide (DMF), methanol $(\mathrm{MeOH})$, sodium hydroxide (NaOH), chloroform $\left(\mathrm{CHCl}_{3}\right)$, tetrahydrofuran (THF), dichloromethane
(DCM) and Methylene Blue (molecular formula: $\mathrm{C}_{16} \mathrm{H}_{18} \mathrm{ClN}_{3} \mathrm{~S} \cdot 3 \mathrm{H}_{2} \mathrm{O}$; molecular weight: 373.9) were purchased from Sigma Aldrich, and Congo Red (molecular formula: $\mathrm{C}_{32} \mathrm{H}_{22} \mathrm{~N}_{6} \mathrm{Na}_{2} \mathrm{O}_{6} \mathrm{~S}_{2}$; molecular weight: 696.68) was purchased from Fluka, and they were used as received.

\subsection{Synthesis of PIM-1}

TTSBI (51.06 g, $0.15 \mathrm{~mol})$, TFTPN (30.01 g, $0.15 \mathrm{~mol})$, anhydrous $\mathrm{K}_{2} \mathrm{CO}_{3}(62.2 \mathrm{~g}, 0.45 \mathrm{~mol})$, DMAc $(300 \mathrm{~mL})$ and toluene $(150 \mathrm{~mL})$ were added under a nitrogen atmosphere to a dry $1 \mathrm{~L}$ three necked round bottom flask equipped with a Dean-Stark trap and mechanical stirrer, in an oil bath pre-heated to $160{ }^{\circ} \mathrm{C}$, and the reaction carried out for $40 \mathrm{~min}$ under reflux. At the end of the reaction, when stirring was stopped, a highly viscous solution formed. The crude polymer was washed with methanol and then dissolved in chloroform and re-precipitated from methanol. The product was refluxed for $4 \mathrm{~h}$ in deionized water and then dried at $110^{\circ} \mathrm{C}$ for two days. Yield: $62 \mathrm{~g}(90 \%)$. GPC: $M_{\mathrm{n}}=106,000$, $M_{\mathrm{w}}=189,000, M_{\mathrm{w}} / M_{\mathrm{n}}=1.78 .{ }^{1} \mathrm{H}$ NMR $\left(400 \mathrm{MHz}, \mathrm{CDCl}_{3}, \mathrm{~d}, \mathrm{ppm}\right)$ : $6.75(2 \mathrm{H}, \mathrm{s}), 6.35$ (2H, s), 2.26-2.09 (4H, dd), 1.40-1.10 (broad, 12H). ATR-IR $\left(\mathrm{cm}^{-1}\right)$ : 2995, 2864, 2239, 1605, 1446, 1264. Anal. calcd for $\mathrm{C}_{29} \mathrm{H}_{20} \mathrm{~N}_{2} \mathrm{O}_{4}$ (wt\%): C: 75.64, H: 4.37, N: 6.08 found: C: 72.2, H: 4.3, N: 6.0 .

\subsection{Hydrolysis of PIM-1}

Dry PIM-1 powder and $\mathrm{NaOH}$ solution $\left(\mathrm{H}_{2} \mathrm{O}\right.$ /ethanol: $\left.1 / 1\right)$ were added to a one neck round-bottom flask equipped with a condenser. The mixture was heated to $120^{\circ} \mathrm{C}$ and left to stir at this temperature under reflux. The reaction stopped and DI water $(40-100 \mathrm{~mL})$ added to this mixture and solid collected by vacuum filtration.

Washing Procedure: Following the filtration of the reaction mixture, two different routes were applied. Method A: Samples were dried in an oven at $110^{\circ} \mathrm{C}$ overnight. Following this, dry samples were placed in acidic water ( $\mathrm{pH}$ was adjusted to $4-5$ by $1 \mathrm{M} \mathrm{HCl}$ unless stated otherwise) and left stirring at room temperature for $2 \mathrm{~h}$. Then they were filtered under vacuum and washed with a copious amount of water. At the final stage, the powder was stirred in water for $2 \mathrm{~h}$ before drying at $110{ }^{\circ} \mathrm{C}$ under vacuum overnight. Finally, the polymer was ground with the help of pestle and mortar to obtain a uniform structure. Method B: Without prior drying, samples were placed in acidic water and then the procedure was followed as described in Method A. Experimental details are given in Table $\mathrm{S} 1$.

\subsection{Electrospinning}

The possible chemical structure of hydrolyzed PIM-1 and the electrospinning process are illustrated in Fig. 1. A certain amount of hydrolyzed PIM-1 powder is dissolved in DMF and left to stir overnight at room temperature to ensure the complete dissolution. For a sample (HP4-fully hydrolyzed) that needs more dissolution, heating was applied for $2 \mathrm{~h}$, then it was stirred overnight at room temperature. In the electrospinning process, a solution of hydrolyzed PIM-1 was placed in a $1 \mathrm{~mL}$ syringe equipped with a blunt needle with an outer diameter of $1.20 \mathrm{~mm}$ and the syringe was positioned horizontally on the syringe pump (KD Scientific, KDS 101). Metal plate collector was covered by an aluminum foil then placed across the syringe to collect microfibers. Extensive optimization studies have been performed for the electrospinning and the applied parameters were as: flow rate of the polymer solution; $0.3-0.6 \mathrm{~mL} \mathrm{~h}^{-1}$, applied voltage; $10-15 \mathrm{kV}$ and tip to collector distance; $10-15 \mathrm{~cm}$. Then, the collected fibers were detached from the aluminum surface and dried in an oven at $110{ }^{\circ} \mathrm{C}$ under vacuum for overnight.

\subsection{Methods}

The molecular weight of PIM-1 was measured by an Agilent gel- 
(a)

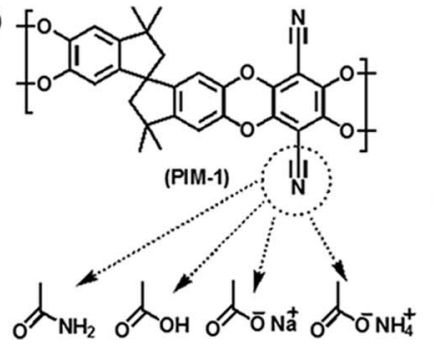

(b)

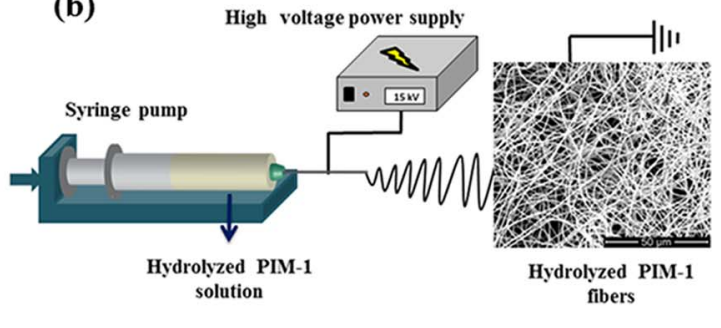

Fig. 1. a) Chemical structure of PIM-1 and possible hydrolysis products, b) illustration of the electrospinning process of hydrolyzed PIM-1 fibers. permeation chromatograph (GPC) equipped with a ZORBAX PSM 300-S column, which was calibrated using polystyrene standard samples. THF was used as mobile phase at a flow rate of $1 \mathrm{mg} \mathrm{mL}^{-1}$. Infrared (IR) spectra of samples were recorded on a Bruker Vertex 70 spectrometer. Samples were mixed with potassium bromide $(\mathrm{KBr})$ and pressed under the pressure of 8 tons to prepare pellets. Each sample was scanned 64 times at a resolution of $4 \mathrm{~cm}^{-1}$. Peak areas were calculated using Omnic software. Ultraviolet (UV) spectra were recorded on a Varian Cary 100 Bio spectrometer. Spectra over the wavelength range 200-800 nm were obtained for DMAc. Polymer samples $(\sim 1 \mathrm{mg})$ were dissolved in solvent $(10 \mathrm{~mL})$. DMAc was used as a blank for baseline correction. ${ }^{1} \mathrm{H}$ nuclear magnetic resonance $\left({ }^{1} \mathrm{H}\right.$ NMR) spectra was recorded using a Bruker DPX-400 MHz spectrometer at room temperature. Polymer solutions were prepared by in $\mathrm{CDCl}_{3}$ or $\mathrm{d}_{6^{-}}$DMSO. Chemical shifts were referenced to tetramethylsilane (TMS). Elemental analysis was carried out using a Thermo Scientific Flash 2000 series CHNS-O analyzer. 2,5-(bis(5-tert-butyl-2-benzo-oxazol-2-yl))thiophene was used as a standard. Samples (1-1.5 mg) were mixed with vanadium pentoxide (8-10 $\mathrm{mg}$ ) that was used as a catalyst for complete oxidation. Scanning electron microscopy (SEM) images were obtained using a FEI Quanta 200 FEG scanning electron microscope. All samples were coated with $5 \mathrm{~nm} \mathrm{Au-Pt}$ prior to imaging and the analysis was performed at $10 \mathrm{kV}$. The diameters of electrospun fibers were quantified using ImageJ software by measuring about 100 different fibers. The viscosity of the solutions used for electrospinning was investigated using Anton Paar Physica MCR 301 Rheometer equipped with cone/ plate accessory (spindle type CP20-4) at $22{ }^{\circ} \mathrm{C}$ and shear rate at $100 \mathrm{~s}^{-1}$. Thermal properties of samples were investigated using thermogravimetric analyzer (TGA, TA Q500) and differential scanning calorimetry (DSC, TA Q2000). The samples were heated to $600{ }^{\circ} \mathrm{C}$ at $20^{\circ} \mathrm{C} \mathrm{min}^{-1}$ under $\mathrm{N}_{2}$ atmosphere for TGA measurements. For DSC measurements, the samples were equilibrated at $0{ }^{\circ} \mathrm{C}$ then heated up to $500{ }^{\circ} \mathrm{C}$ at $20^{\circ} \mathrm{C} \mathrm{min}{ }^{-1}$ under $\mathrm{N}_{2}$ atmosphere. $\mathrm{N}_{2}$ adsorption/desorption isotherms at $-196{ }^{\circ} \mathrm{C}$ were measured using an autosorb iQ gas sorption analyzer. A small amount of sample $(\sim 0.1 \mathrm{~g})$ was weighed into an analysis tube and degassed under high vacuum at $120^{\circ} \mathrm{C}$ for $960 \mathrm{~min}$. Analysis was conducted after reweighing the degassed sample. Brunauer-Emmet-Teller (BET) surface areas were calculated from $\mathrm{N}_{2}$ adsorption isotherms by multi-point analysis. For dye adsorption studies, aqueous stock solutions of Methylene Blue and Congo Red were prepared in deionized water. Different concentrations were prepared by dilution of the stock solutions with deionized water. Calibration solutions were prepared from 20 to $1.25 \mathrm{mg} \mathrm{L}^{-1}$ and their absorbance were measured using a Varian Cary 100 Bio spectrometer. Values of $\lambda_{\max }$ for Methylene Blue and Congo Red were taken as 664 and $498 \mathrm{~nm}$, respectively. Specific absorption coefficients, $a$, were determined as $0.1808 \mathrm{~L} \mathrm{mg}^{-1} \mathrm{~cm}^{-1}$ for Methylene Blue and $0.0292 \mathrm{~L} \mathrm{mg}^{-1} \mathrm{~cm}^{-1}$ for Congo Red. An exact amount of oven-dried adsorbent $(\sim 5.0 \mathrm{mg})$ was placed in $80-20 \mathrm{~mL}$ of $20 \mathrm{mg} \mathrm{L}^{-1}$ dye solution. The dye solution (at natural $\mathrm{pH}$ ) containing the adsorbent was stirred well with a magnetic stirrer for $24 \mathrm{~h} .3 \mathrm{~mL}$ aliquots were taken by syringe and filtered through a PTFE hydrophobic filter $(0.45 \mathrm{~mm})$. The mass of dye adsorbed by the polymer, $q_{\mathrm{e}}\left(\mathrm{mg} \mathrm{g}^{-1}\right)$, was determined from the absorbance of the dye solution before contact with polymer, $A_{0}$, and the absorbance of the dye solution after reaching effective equilibrium with the polymer, $A_{\mathrm{e}}$, using Eq. (1).

$q_{\mathrm{e}}=\frac{\left(A_{0}-A_{\mathrm{e}}\right) V}{\operatorname{alm}}$

where $V$ is the total volume of dye solution, $l$ is the path length in the spectrometer and $m$ is the total mass of polymer.

The adsorption experiments were also studied using concentrated Methylene Blue solutions from 50 to $500 \mathrm{mg} \mathrm{L}^{-1}$. An exact amount of oven-dried adsorbent $(\sim 5.0 \mathrm{mg})$ was placed in $20 \mathrm{~mL}$ of Methylene Blue solutions and stirred for $24 \mathrm{~h}$ to calculate maximum adsorption capacity of adsorbents. In the filtration experiment, hydrolyzed PIM-1 fiber membrane with a diameter of $\sim 4 \mathrm{~cm}$, a mass of $0.12 \mathrm{~g}$ and a thickness of $0.18 \mathrm{~mm}$ was used. $500 \mathrm{~mL} 20 \mathrm{mg} \mathrm{L}^{-1}$ of Methylene Blue solution was used and solution was added as $100 \mathrm{~mL}$ portions. After the filtration of each $100 \mathrm{~mL}$, samples were taken and the removal efficiency of the membrane was calculated. Once $500 \mathrm{~mL}$ was completely filtered, the total solution was passed through the same membrane four times, and for each time the removal efficiency was calculated. \% Removal efficiency was calculated based on the Eq. (2).

$\%$ Removal efficieny $=\frac{\left(\mathrm{A}_{0}-\mathrm{A}_{\mathrm{e}}\right)}{\mathrm{A}_{0} \times 100}$

\section{Results and discussion}

\subsection{Structural characterization of hydrolyzed PIM-1s}

Base catalyzed hydrolysis of PIM-1 was first reported in 2009 as "carboxylated PIMs" by Due et al. [36] The structure of these products was proposed as carboxylic acid structures and amide intermediate was not mentioned in that study. Lately, base catalyzed hydrolysis of PIM-1 was studied by our group and the possible chemical structure of hydrolysis products was re-considered using the combination of various equations that obtained by several different techniques showing amide structure is the predominant structure along with carboxylic acids, ammonium carboxylate and sodium carboxylate structures [35]. Even though several researchers have studied the hydrolysis of PIM-1, recent publications revealed that the amide intermediate has been overlooked in these studies [43-47]. Santoso et al. [48] has conducted a detailed study to investigate the synthesis of carboxylated PIMs which supports our claims about the amide structure in hydrolysis reaction [35]. Thus, the same approach was applied to analyze the samples prepared in this work for the characterization of hydrolysis products. Fig. 2 depicts the IR spectra of PIM-1 and hydrolyzed PIM-1 powders. The PIM-1 powder shows characteristic nitrile stretches $\left(2240 \mathrm{~cm}^{-1}\right)$. After the hydrolysis, the relative intensity of nitrile is reduced and new bands appeared in the region $3000-3500 \mathrm{~cm}^{-1}$ along with a carbonyl peak at $\sim 1700 \mathrm{~cm}^{-1}$ that may indicate either amide or carboxylic acid structure, as explained in detail previously $[35,36]$. UV visible spectra of PIM-1 and hydrolyzed PIM-1s are depicted in Fig. 3. PIM-1 shows two characteristic signals with $\lambda_{\max }$ values of 300 and $440 \mathrm{~nm}$ and the intensity of the peak at $444 \mathrm{~nm}$ reduces by hydrolysis reaction while new peak appears in $384 \mathrm{~nm}$. These two peaks ( 384 and $444 \mathrm{~nm}$ ) represents unconverted nitrile, and the peak at $326 \mathrm{~nm}$ is associated with 


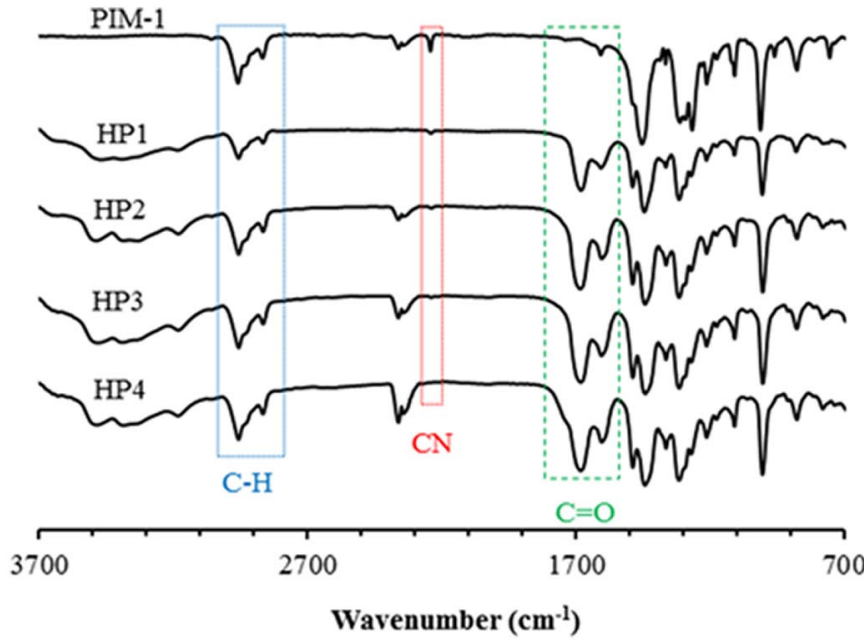

Fig. 2. IR spectra of PIM-1 and hydrolyzed PIM-1 samples HP1 (20\% NaOH, 2 h), HP2 (20\% NaOH, 2.5 h), HP3 (25\% NaOH, 2 h) and HP4 (25\% NaOH, 3 h).

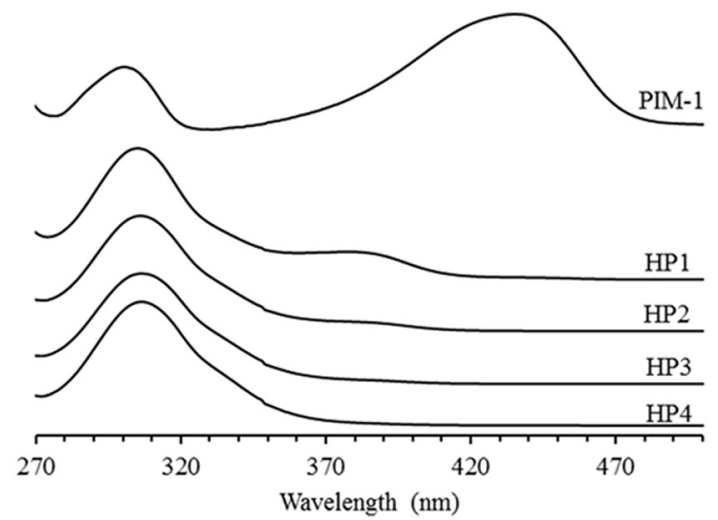

Fig. 3. UV spectra of PIM-1 and hydrolyzed PIM-1 samples HP1 (20\% NaOH, 2 h), HP2 (20\% $\mathrm{NaOH}, 2.5 \mathrm{~h})$, HP3 (25\% NaOH, $2 \mathrm{~h}$ ) and HP4 (25\% NaOH, 3 h).

converted species [35].

Hydrolysis was also confirmed by NMR spectroscopy. Fig. 4 displays ${ }^{1} \mathrm{H}$ NMR spectra of PIM-1 and hydrolyzed PIM-1 with different degrees of hydrolysis. Elemental analysis of samples were also obtained and the degree of hydrolysis was calculated based on the previous approach [35] using Eq. S1 and S2 in the Supplementary information. The results are displayed in Table 1. Further characterization data (IR, UV-visible spectra) are provided in the Supplementary information (Fig. S1-S2). Also, the comparison of the calculated values of percentage hydrolysis from UV and IR are shown in the Supplementary information in Fig. S3, which illustrates good agreement.

Hydrolyzed PIMs show similar characteristic signals on characterization, regardless of their degree of hydrolysis. However, it was found that solubility can differ greatly, depending on the applied reaction conditions and washing procedures. PIM-1 is soluble in common organic solvents such as THF, $\mathrm{CHCl}_{3}$ and DCM, but is insoluble in DMF and DMAc. After hydrolysis, the polymer becomes soluble in polar aprotic solvents such as DMF and DMAc and is no longer soluble in THF, $\mathrm{CHCl}_{3}$ and DCM $[14,36]$. As we mentioned previously [35], the degree of hydrolysis strongly depends on the percentage of the base used in the hydrolysis reaction. In the current study, we extended the previous work by using 25, 20 and $10 \%(\mathrm{w} / \mathrm{v}$ ) $\mathrm{NaOH}$ solutions. The results show that even though a high degree of hydrolysis is obtained with $10 \%(\mathrm{w} / \mathrm{v}) \mathrm{NaOH}$ solution at a long reaction time, the product obtained does not show good solubility. Good solubility refers here to more than $20 \%(\mathrm{w} / \mathrm{v})$ of polymer in a solvent. However, the resulting polymers show good processability when they are hydrolyzed by 20 and
$25 \%(\mathrm{w} / \mathrm{v}) \mathrm{NaOH}$ solutions, if the washing procedure is followed in the right order.

Several different samples have been studied to confirm the present data. According to our findings, when polymer samples are dried immediately after the reaction (Method A), hydrolyzed PIMs show enhanced solubility. However, if washing continues (Method B) after the reaction has stopped, the solubility of the resulting polymer is hindered, possibly because strong hydrogen bonds inhibit the access of solvent. This is investigated by samples HP3 and HP10 (Table 1). Both samples have a high degree of hydrolysis (greater than 90\%) but the applied washing procedure strongly defines the solubility of the product. When HP3 was produced and washed by method B the polymer became swollen in DMF and DMAc. Even after a long period of heating, only $5-6 \%$ polymer was able to dissolve in the solvent. However, after a short reaction repeat and washing by method A, the solubility of the polymer was enhanced up to $65 \%$. Reproducibility of this method was confirmed by the sample HP10. The sample was divided into two parts and different washing methods were applied for the identical samples (HP10 and HP10-2). While method A gives highly soluble material, Method B gives a product that has a partial solubility in DMF. Moreover, it was observed that soluble products are slightly brownish compared to their less soluble counterparts. Visual differences based on the applied washing methods are depicted in the Supplementary information in Fig. S4.

HP5 was also prepared by method B and the results were similar. Higher than $70 \%$ conversion was obtained but solubility was not good. On the other hand, HP1 shows less than $70 \%$ conversion (method A) but shows good solubility. Hence, these two samples also support the significance of the washing procedure. In addition to this, grinding was applied to the polymer (HP7-9) after the first drying step (before acidification) to acidify the material more easily as the polymer has low contact with water. However, we found that grinding at this stage only makes filtration difficult and time-consuming, due to the small and well-dispersed particles in water.

\subsection{Electrospinning}

Four different hydrolyzed PIM-1 samples, HP1 (65\% hydrolyzed), HP2 (86\% hydrolyzed), HP3 (94\% hydrolyzed) and HP4 (99\% hydrolyzed), were chosen to produce fibers by the electrospinning process, as they showed good solubility for the preparation of electrospinning polymer solutions. The effect of a base concentration and the reaction time used in hydrolysis on a fiber formation was also considered. While HP1 (65\% hydrolyzed) and HP2 (86\% hydrolyzed) were both produced by $20 \% \mathrm{NaOH}$ solution in 2 and 2.5 h, respectively (Table S1). HP2 required more concentrated solution compared to HP1 for fiber formation (Table 2). Similar trend was observed in samples HP3 (94\% hydrolyzed) and HP4 (99\% hydrolyzed) which were produced by $25 \%$ $\mathrm{NaOH}$ solution in 2 and $3 \mathrm{~h}$, respectively. While HP4 required $120 \%$ polymer solution, HP3 only required $62 \%$ polymer solution for fiber formation. Longer reaction times were also attempted, to produced higher degrees of hydrolysis along with higher degrees of carboxylation, but we found that maximum hydrolysis time that enables beadfree fiber formation was found $3 \mathrm{~h}$. The higher the degree of hydrolysis, the more concentrated the spinning solutions needed to be (Table 2) depending on the reaction conditions used in hydrolysis. Even though PIM-1 is thermally and chemically stable against acidic and basic conditions [14,49-51], long reaction times in a concentrated base may damage the ether linkages in polymer backbone which required more concentrated polymeric solution for electrospinning of uniform fibers. This idea was supported not only by viscosity measurements but also by BET surface area measurements (Table 2). As can be seen, the viscosity of HP1 and HP2 shows significant difference. Even though they have been prepared by different solution concentrations, their average fiber diameters are quite close to each other indicating long reaction time reduces the molecular weight of the polymer. Considering their powder 


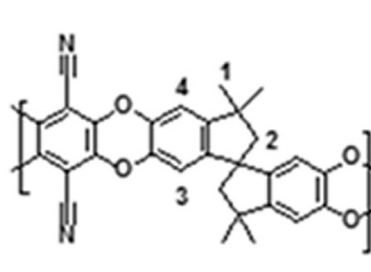

5

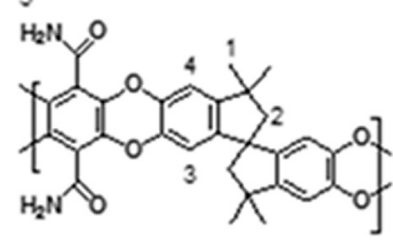

5

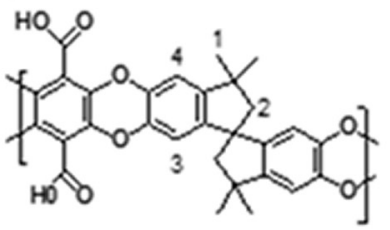

DMSO

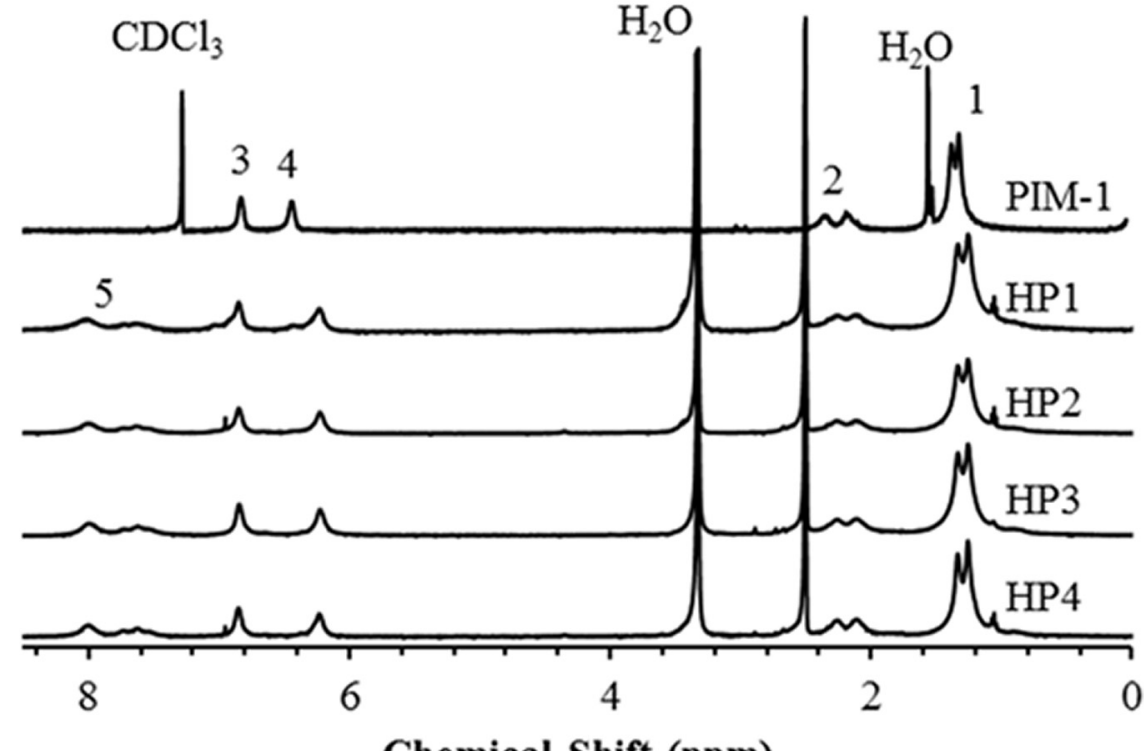

Fig. 4. ${ }^{1} \mathrm{H}$ NMR spectra of PIM-1 and hydrolyzed PIM-1 samples HP1 (20\% NaOH, 2 h), HP2 (20\% NaOH, 2.5 h), HP3 (25\% NaOH, $2 \mathrm{~h})$ and HP4 (25\% NaOH, 3 h).

\section{Chemical Shift (ppm)}

and fiber BET surface area data, PIM-1 powder shows quite high BET surface with $767 \mathrm{~m}^{2} \mathrm{~g}^{-1}$. Hydrolyzed PIM powders shows relatively reduced surface area depending on reaction time and base used for hydrolysis reaction. This may also indicate the reduction in molecular weight. Similar comparison can be done by sample HP3 and HP4. The higher the reaction time and base concentration result in the more reduction in the surface area and the more viscous solution for electrospinning. The complete $\mathrm{N}_{2}$ adsorption desorption data are provided in the Supplementary information Fig. S5 (a-e).

In addition, electrospun hydrolysed PIMs shows significant reduction in their BET surface area compared to their powder forms which may be explained by their interaction by spinning solvent. For this purpose, TGA measurements were conducted and hydrolyzed PIM-1 fibers were compared with parent PIM-1 and hydrolysed PIM-1 powders. Fig. 5(a) displays that while PIM-1 powder shows no significant weight loss up to $460{ }^{\circ} \mathrm{C}$, hydrolysed PIM-1 (HP4) powder shows several degradation steps starting from $150{ }^{\circ} \mathrm{C}$ which was explained by functional group degradations in our previous paper [35] showing less thermal stability compared to parent PIM-1 polymer. However, fiber and powder forms of hydrolysed PIM-1 show only slight difference revealing no significant DMF present in the electrospun fibers.

PIM-1 is a non-crystalline/amorphous polymer which does not show any $T_{\mathrm{g}}$ before its degradation temperature since $T_{\mathrm{g}}$ is higher than the degradation temperature. It only shows degradation $\left(T_{\mathrm{d}}\right)$ around $440{ }^{\circ} \mathrm{C}$ (Fig. 5b) and similar observations have been reported previously [52]. Even though several reports have been published until now $[35,36]$, no

Table 1

Data from UV, IR, Elemental analysis and ${ }^{1} \mathrm{H}$ NMR spectroscopy, and \% hydrolysis calculated by UV and IR of hydrolyzed products.

\begin{tabular}{|c|c|c|c|c|c|c|c|c|c|c|c|}
\hline \multirow[t]{2}{*}{ Sample code ${ }^{a}$} & \multicolumn{3}{|c|}{ UV absorbance in DMAc } & \multicolumn{2}{|l|}{ Infrared } & \multicolumn{3}{|c|}{ Elemental analysis } & \multirow{2}{*}{$\frac{\mathrm{NMR}}{I_{\mathrm{CO}-\mathrm{H}} / I_{\mathrm{Ar}-\mathrm{H}}}$} & \multicolumn{2}{|c|}{$\%$ hydrolyzed } \\
\hline & $326 \mathrm{~nm}$ & $384 \mathrm{~nm}$ & $444 \mathrm{~nm}$ & $I_{\mathrm{CH}}$ & $I_{\mathrm{CN}}$ & $\mathrm{C}$ & $\mathrm{N}$ & $\mathrm{H}$ & & UV & IR \\
\hline PIM-1 & & & & 2978.2 & 183.4 & 72.2 & 6.0 & 4.3 & & & 0 \\
\hline HP1 & 0.62 & 0.26 & 0.02 & 1493.0 & 32.0 & 64.1 & 5.0 & 4.6 & 1.00 & 69 & 65 \\
\hline HP2 & 0.82 & 0.11 & 0.00 & 2753.9 & 23.2 & 65.4 & 5.0 & 4.9 & 0.91 & 88 & 86 \\
\hline HP3 & 1.35 & 0.09 & 0.00 & 2900.0 & 10.4 & 66.6 & 4.9 & 4.9 & 0.85 & 94 & 94 \\
\hline HP4 & 0.68 & 0.03 & 0.00 & 2932.8 & 1.4 & 65.5 & 4.2 & 5.0 & 0.79 & 96 & 99 \\
\hline HP5 & 0.65 & 0.17 & 0.10 & 1912.0 & 30.6 & 66.8 & 5.2 & 5.0 & & 70 & 74 \\
\hline HP6 & 1.57 & 0.11 & 0.01 & 2936.0 & 13.9 & & & & & 93 & 92 \\
\hline HP7 & 1.37 & 0.10 & 0.02 & 3758.5 & 9.0 & 63.1 & 4.6 & 4.7 & & 92 & 96 \\
\hline HP8 & 0.86 & 0.04 & 0.01 & 2406.0 & 0.7 & 64.2 & 3.7 & 4.8 & & 95 & 100 \\
\hline HP9 & 0.58 & 0.02 & 0.00 & 3512.0 & 1.2 & 62.5 & 3.5 & 4.7 & & 97 & 99 \\
\hline HP10 & 1.47 & 0.11 & 0.00 & 2212.3 & 8.0 & 65.3 & 5.1 & 4.9 & & 93 & 94 \\
\hline HP10-2 & 1.53 & 0.14 & 0.01 & 2733.0 & 5.8 & 65.7 & 5.2 & 4.9 & & 91 & 97 \\
\hline HP11 & 0.41 & 0.13 & 0.02 & 3907.0 & 74.7 & 67.2 & 5.2 & 4.9 & & 73 & 69 \\
\hline HP12 & 0.47 & 0.10 & 0.01 & 2521.0 & 25.0 & 67.2 & 6.1 & 5.1 & & 82 & 84 \\
\hline
\end{tabular}

${ }^{\text {a }}$ Sample codes for the reaction products: $\mathrm{HP}=$ hydrolyzed PIM-1, number = sequence of the experiment. 
Table 2

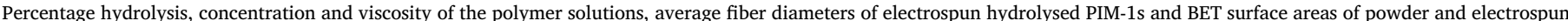
samples.

\begin{tabular}{|c|c|c|c|c|c|c|}
\hline \multirow[t]{2}{*}{ Sample code } & \multirow[t]{2}{*}{$\%$ hydrolysis $^{\mathrm{a}}$} & \multirow[t]{2}{*}{ Concentration of the solution $(\% \mathrm{w} / \mathrm{v})$} & \multirow[t]{2}{*}{ Viscosity (Pa s) } & \multirow[t]{2}{*}{ Average fiber diameter $(\mu \mathrm{m})$} & \multicolumn{2}{|c|}{$\operatorname{BET}\left(\mathrm{m}^{2} \mathrm{~g}^{-1}\right)$} \\
\hline & & & & & Powder & Fiber \\
\hline PIM-1 & - & - & - & - & 767 & - \\
\hline HP1 & 65 & 40 & 0.13 & $1.21 \pm 0.15$ & 519 & 320 \\
\hline HP2 & 86 & 62 & 0.29 & $1.15 \pm 0.16$ & 451 & 87 \\
\hline HP3 & 94 & 60 & 0.23 & $0.58 \pm 0.08$ & 410 & 65 \\
\hline HP4 & 99 & 120 & 4.77 & $0.76 \pm 0.09$ & 345 & 25 \\
\hline
\end{tabular}

${ }^{\text {a }}$ Calculated based on IR.

(a)

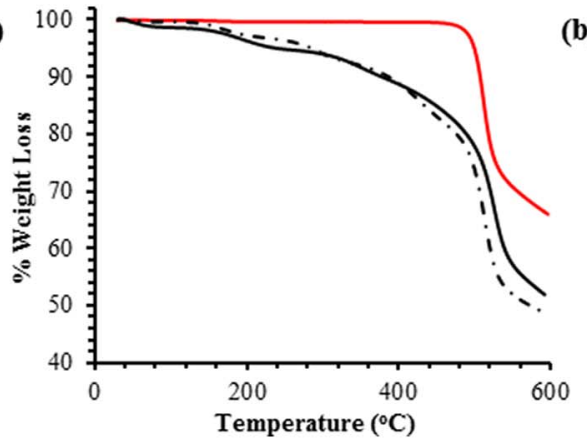

(b)

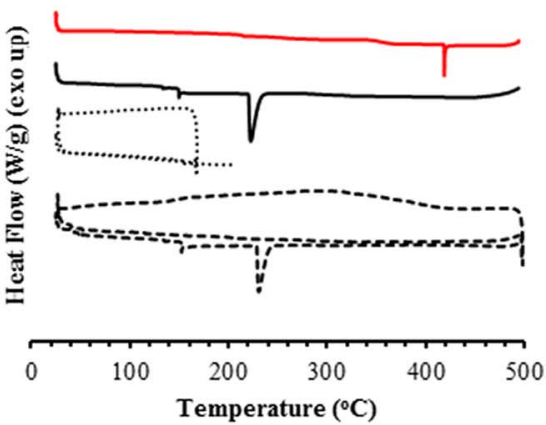

Fig. 5. (a) TGA curves, (b) DSC curves of PIM-1 and hydrolyzed PIM-1 samples. PIM-1 powder (red solid line), HP4 powder (black solid line) and HP4 fiber (black dashed line). (For interpretation of the references to colour in this figure legend, the reader is referred to the web version of this article.)
DSC data has been supported related to hydrolysed PIMs. Here, we examined hydrolysed PIMs (HP4) DSC curve. It can be clearly seen that, both hydrolysed PIMs (HP4 powder and HP4 fiber) show two different degradation steps; one is around $150{ }^{\circ} \mathrm{C}$ and other one is around $230{ }^{\circ} \mathrm{C}$ (Fig. 5b). Both steps have been studied separately as a complete cycle in order to confirm the degradation and the results are displayed in Fig. 5(b). At first glance, the degradation at $150{ }^{\circ} \mathrm{C}$ was explained as a $T_{\mathrm{g}}$ but the further study with complete cycle has revealed that the change can only be explained by functional group degradation. The complete data related to thermal properties of hydrolyzed PIM fibers are provided in the Supplementary information (Fig. S6 (a) and (b)).

The effect of solvent volatility on electrospun fibers was previously studied by our group [53]. The research indicated that while volatile solvents results in ribbon-like fibers, less volatiles solvents such as DMF and DMAc result in round fibers. Smooth and bead-free uniform ultrafine fibers were produced by electrospinning of hydrolyzed PIM-1 in DMF. Here, synthesis of hydrolyzed PIM-1 having high solubility gave us the possibility to obtained electrospun hydrolyzed PIM-1 ultrafine fibers with uniform morphology. This approach is quite valuable in contrast to what has been reported by Zhang et al. [43] where the precursor PIM-1 polymer was first electrospun into fibers and subsequently hydrolyzed, which resulted in fragile fibers that fractured into pieces and having rougher surfaces. In our case, the electrospun hydrolyzed PIM-1 fibrous membranes have shown mechanical integrity to be further used as a filtering material. Fig. 6 depicts the SEM images and fiber diameter distributions of hydrolyzed PIM-1 fibers with different degree of hydrolysis. The average fiber diameters of the hydrolyzed PIM-1 $\mathrm{s}$ were found to be in the range from $0.58 \pm 0.15 \mu \mathrm{m}$ to $1.21 \pm 0.15 \mu \mathrm{m}$, depending on the degree of hydrolysis (Table 2).

\subsection{Dye adsorption}

It has been known that PIM-1 shows high affinity for neutral species $[54,55]$ and hydrolyzed PIMs show high affinity for cationic species $[35,42,43]$. In this study, the adsorption ability of hydrolyzed PIM-1 electrospun nanofibrous membranes with different degrees of hydrolysis have been tested for Methylene Blue (cationic) and Congo Red (anionic) dyes from an aqueous system. The study has been carried out in two different sets of experiments. One was aimed to compare the adsorption capacities of PIM-1 powder and of hydrolysed PIMs fibers against Methylene Blue and Congo Red dyes without using any dilution ( $20 \mathrm{mg} \mathrm{L}^{-1}$ solutions). The other one was designed to find the theoretical max adsorption capacities of hydrolysed PIMs against Methylene Blue by using concentrated dye solutions.

The first part of our results confirmed that hydrolyzed PIM-1 nanofibrous membranes exhibited high affinity for Methylene Blue as consistent with the literature findings $[35,42,43]$. In the present work, while PIM-1 in the powder form has shown only $10 \mathrm{mg} \mathrm{g}^{-1}$ and $16 \mathrm{mg} \mathrm{g}^{-1}$ adsorption for Congo Red and Methylene Blue, respectively, fully hydrolyzed PIM-1 (HP4) fibrous membrane has shown $4 \mathrm{mg} \mathrm{g}^{-1}$ and $157 \pm 16 \mathrm{mg} \mathrm{g}^{-1}$ adsorption for the respective dyes in $20 \mathrm{mg} \mathrm{L}^{-1}$ solutions. Fig. 7a illustrates the UV-visible absorption spectra of Congo Red and Methylene Blue solutions before and after contact with fully hydrolyzed PIM-1 (HP4) fibrous membrane. Fig. 7b exhibits the adsorption maximum for PIM-1 powder and hydrolyzed PIM-1 fibrous membrane with different degrees of hydrolysis against Congo Red and Methylene Blue dyes in $20 \mathrm{mg} \mathrm{L}^{-1}$ solutions. The adsorption data are provided in the Supplementary information (Table S2, 3 and 5).

The second part or adsorption experiments showed that the experimental maximum adsorption capacity of hydrolysed PIMs can reach up to $272 \mathrm{mg} \mathrm{g}^{-1}$ based on the degree of hydrolysis (Fig. 8a) which is quite close the value of theoretical maximum adsorption capacity $\left(278 \mathrm{mg} \mathrm{g}^{-1}\right.$ ) calculated by using Langmuir parameters that can be found in detail in Table S4 in Supplementary information. Fig. 8 (b) and (c) show Langmuir and Freundlich models for adsorption of Methylene Blue on hydrolysed PIMs. Unlike previously reported data [43], the present data confirms that Langmuir model is more favorable than Freundlich model indicating monolayer formation of Methylene Blue on hydrolyzed PIM surface. The data is also in good agreement with similar study which was conducted by Shakeel et al. [56]. Langmuir model is also favored in the adsorption of methyl orange on PIM-1 powder.

Even though the hydrolyzed PIMs highest uptake is lower than the commercial activated carbon and other most promising adsorbent materials [57], the ability to form as a membrane enables them to employ hydrolysed PIM fibers as a self-standing membrane in filtration 

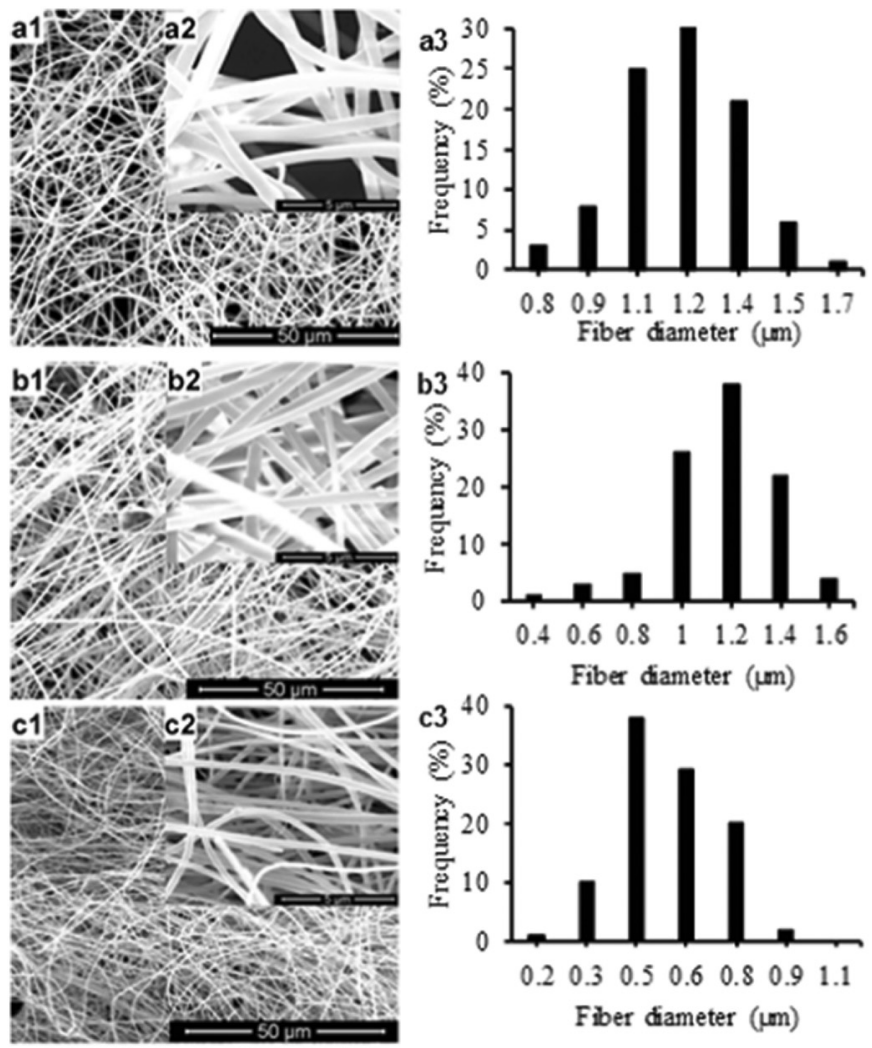

Füber diameter $(\mu \mathrm{m})$
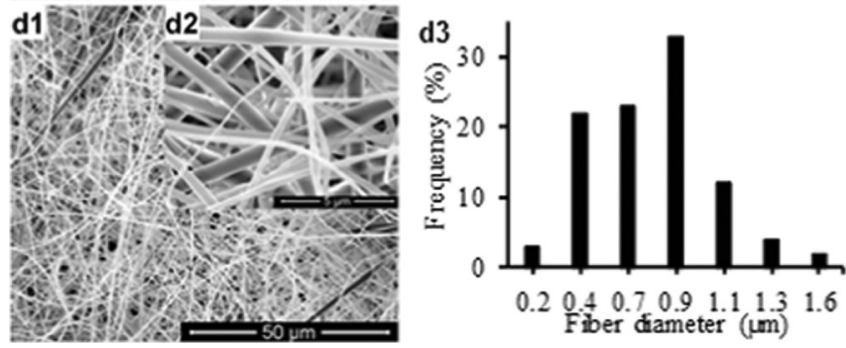

Fig. 6. SEM images of (a1) HP1(65\% hydrolyzed), (b1) HP2 (86\% hydrolyzed), (c1) HP3 (94\% hydrolyzed) and (d1) HP4 (99\% hydrolyzed). (a2-d2) higher magnifications (5 $\mu \mathrm{m})$ and (a3-d3) fiber diameter distributions of corresponding samples.

applications. Thus, following the electrospinning, the hydrolyzed PIM-1 electrospun ultrafine fibers formed self-standing fibrous membranes having mechanical integrity which can be used as a filtering material. Fig. 9a shows the fibrous membrane form of hydrolyzed PIM-1 (HP3) before and after filtration of Methylene Blue aqueous solution, and illustrates the filtration process. Previously, self-standing PIM-1 membranes (solution cast) have been studied for pressure-driven nanofiltration $[16,54,55]$. PIM-1 fibers with additives have also been used in filtration experiments [33]. In so far as we are aware, this is the first report of a electrospun ultrafine fibrous self-standing hydrolyzed PIM membrane for filtration. Here, Methylene Blue was removed from solution by a gravity-fed process using a hydrolyzed PIM-1 fibrous membrane (see Supplementary video 1 ).

The relationship between removal efficiency of hydrolyzed PIM-1 fibrous membrane against filtered volume of Methylene Blue solution (Fig. 9b) and against filtration cycle (Fig. 9c) was also studied by the same membrane. The solution was filtered and removal efficiency was calculated based on the filtered volume. At the early stages of filtration, the removal efficiency was high (over 99.8\%), but over the time the adsorption ability of the membrane was reduced and removal efficiency decreased to $80 \%$. This behavior was expected as the adsorption rate is higher at the initial stage and reduced by the time. Moreover, repeating the filtration cycles also provides an evidence for this approach. While the removal efficiency was $80 \%$ in the first filtration cycle, the efficiency increased gradually up to $96 \%$ after the fourth filtration cycle (Fig. 9c). Furthermore, hydrolyzed PIM-1 fibers keep the fiber morphology after the adsorption experiment as it displayed in Fig. 9a with SEM images before and after in contact with dye solutions.

\section{Conclusions}

This research aimed to investigate systematic hydrolysis of PIM-1 in the presence of sodium hydroxide by varying the concentration of base, washing procedure and the time of the reaction in order to obtain hydrolyzed PIM-1s via electrospinning. PIM-1s with different degrees of hydrolysis along with sufficient solubility were successfully achieved which enables the electrospinning of self-standing nanofibrous membrane for filtration of wastewater. The hydrolysis products became highly soluble when hydrolysis was conducted with 20 or $25 \%(\mathrm{w} / \mathrm{v})$ ratio of base and with drying prior to the washing procedure. Extensive optimization studies were performed for the electrospinning of uniform and bead-free ultrafine fibers from hydrolyzed PIM-1 with different degree of hydrolysis $(65 \%, 86 \%, 94 \%$ and $99 \%)$. The fiber diameters range from 0.6 to $1.2 \mu \mathrm{m}$ depending on the degree of hydrolysis. The hydrolyzed PIM-1 self-standing nanofibrous membrane demonstrated high affinity for a Methylene Blue compare to Congo Red dye. The maximum adsorption capacity of fully hydrolysed PIM-1 for Methylene Blue was found $157 \pm 16 \mathrm{mg} \mathrm{g}^{-1}$ when the adsorption was conducted by $20 \mathrm{mg} \mathrm{L}^{-1}$ dye solution without using any dilution. Futhermore, experimental maximum Methylene Blue adsorption capacity of fully hydrolyzed PIM-1 was found $272 \mathrm{mg} \mathrm{g}^{-1}$. Hydrolyzed PIM-1 fibers were used as a self-standing membrane material for the separation of Methylene Blue from an aqueous solution. Electrospun hydrolyzed PIM1 fibers could adsorb a large amount of Methylene Blue from an aqueous system without the necessity of additional driving force.

\section{Acknowledgments}

T. Uyar acknowledges The Turkish Academy of Sciences -
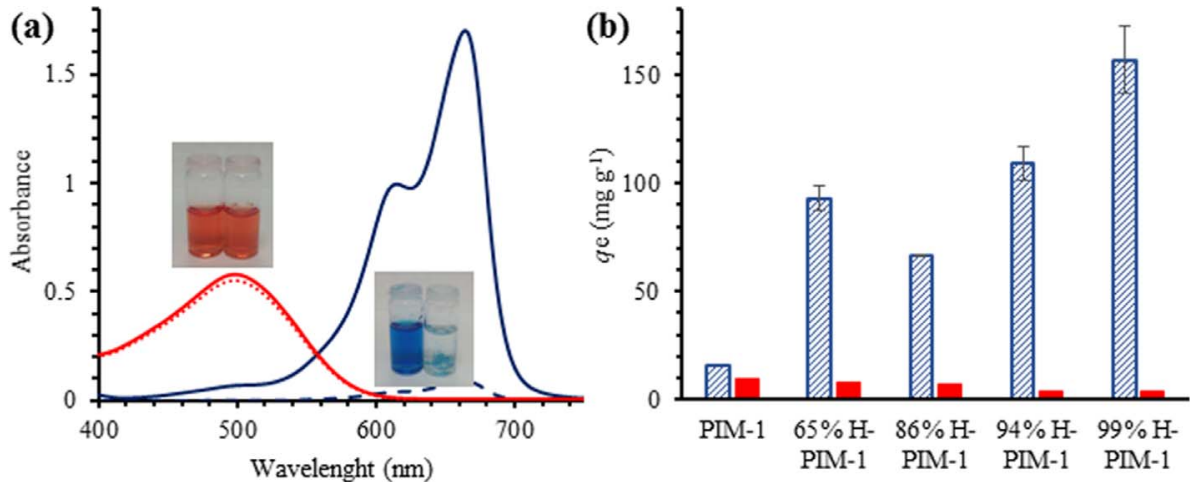

Fig. 7. (a) UV-vis absorption spectra of the aqueous solution of Congo Red and Methylene Blue before (solid blue lines) and after (dashed red lines) contact with fully hydrolyzed PIM-1 (HP4) fibrous membrane, (b) the adsorption capacities of the PIM-1 powder and hydrolyzed PIM-1 fibrous membranes for Congo Red (solid bar) and Methylene Blue (shaded bar) dyes in $20 \mathrm{mg} \mathrm{L}^{-1}$ solutions. (For interpretation of the references to colour in this figure legend, the reader is referred to the web version of this article.) 

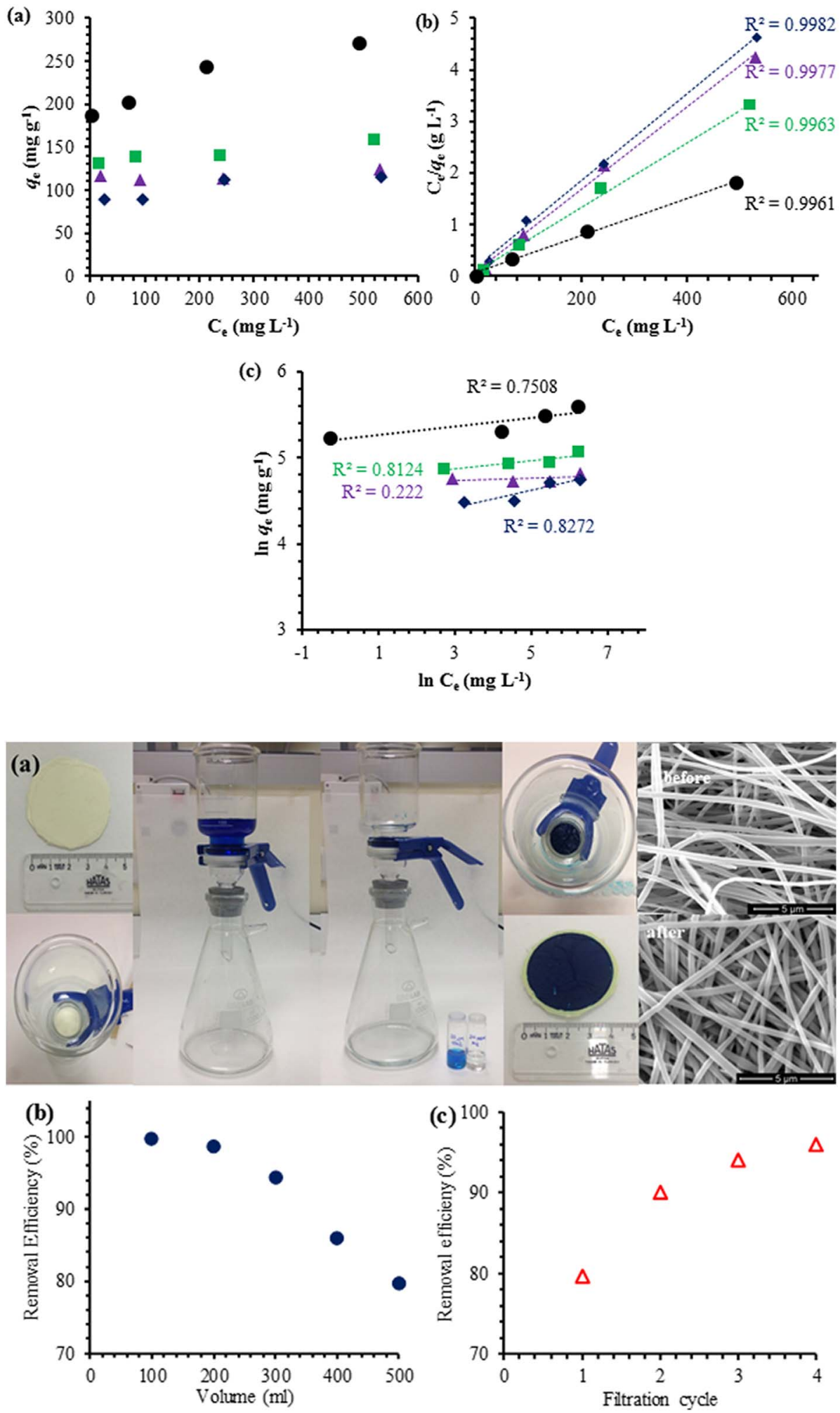

Fig. 8. (a) Adsorption isotherms of Methylene Blue on hydrolyzed PIMs, (b) Langmuir and (c) Freundlich models for adsorption of Methylene Blue on hydrolyzed PIMs. (A) HP1(65\% hydrolyzed), ( ) HP2 (86\% hydrolyzed), ( HP3 (94\% hydrolyzed) and (•) HP4 (99\% hydrolyzed).
Fig. 9. (a) The filtration process of Methylene Blue dye by hydrolyzed PIM-1 (HP3) fibrous membrane and the digital images and SEM images of self-standing hydrolyzed PIM-1 fibrous membrane before and after the filtration of Methylene Blue. The removal efficiency (\%) of hydrolyzed PIM-1 fibrous membrane against (b) the volume of filtered dye solution (๑) and (c) against the filtration cycle $(\Delta)$.
Outstanding Young Scientists Award Program (TUBA-GEBIP)-Turkey for partial funding. The authors would like to thank Dr. Osman Arslan for his practical help.

Supplementary data to this article can be found online at https:// doi.org/10.1016/j.reactfunctpolym.2017.10.019.

\section{References}

[1] C. Grandclément, I. Seyssiecq, A. Piram, P. Wong-Wah-Chung, G. Vanot, N. Tiliacos,
N. Roche, P. Doumenq, From the conventional biological wastewater treatment to hybrid processes, the evaluation of organic micropollutant removal: a review, Water Res. 111 (2017) 297-317.

[2] H. Jayasantha Kumari, P. Krishnamoorthy, T.K. Arumugam, S. Radhakrishnan, D. Vasudevan, An efficient removal of crystal violet dye from waste water by adsorption onto TLAC/Chitosan composite: A novel low cost adsorbent, Int. J. Biol. Macromol. 96 (2017) 324-333.

[3] Y. Cui, X.-Y. Liu, T.-S. Chung, M. Weber, C. Staudt, C. Maletzko, Removal of organic micro-pollutants (phenol, aniline and nitrobenzene) via forward osmosis (FO) process: evaluation of $\mathrm{FO}$ as an alternative method to reverse osmosis (RO), Water Res. 91 (2016) 104-114. 
[4] A.K. An, J. Guo, E.-J. Lee, S. Jeong, Y. Zhao, Z. Wang, T. Leiknes, PDMS/PVDF hybrid electrospun membrane with superhydrophobic property and drop impact dynamics for dyeing wastewater treatment using membrane distillation, J. Membr. Sci. 525 (2017) 57-67.

[5] R. Kakarla Raghava, G.G. Vincent, H. Mahbub, Carbon functionalized $\mathrm{TiO}_{2}$ nanofibers for high efficiency photocatalysis, Mater. Res. Express 1 (1) (2014) 015012.

[6] A. Md Showkat, Y.P. Zhang, S.K. Min, A. Iyengar Gopalan, K. Raghava Reddy, K.S. Lee, Analysis of heavy metal toxic ions by adsorption onto amino-functionalized ordered mesoporous silica, Bull. Kor. Chem. Soc. 28 (2007) 1985-1992.

[7] K. Raghava Reddy, K. Nakata, T. Ochiai, T. Murakami, D. Tryk, A. Fujishima, Facile fabrication and photocatalytic application of $\mathrm{Ag}$ nanoparticles- $\mathrm{TiO}_{2}$ nanofiber composites, J. Nanosci. Nanotechnol. 11 (2011) 3692-3695.

[8] K.R. Reddy, K.V. Karthik, S.B.B. Prasad, S.K. Soni, H.M. Jeong, A.V. Raghu, Enhanced photocatalytic activity of nanostructured titanium dioxide/polyaniline hybrid photocatalysts, Polyhedron 120 (2016) 169-174.

[9] G. Sun, D. Zhang, X. An, M.S. Jahan, J. Zhou, Y. Ni, A case study for integrated forest biorefinery: recovery of manool from evaporator condensate of a kraft pulp mill, Sep. Purif. Technol. 165 (2016) 27-31.

[10] C. Safi, G. Olivieri, R.P. Campos, N. Engelen-Smit, W.J. Mulder, L.A.M. van den Broek, L. Sijtsma, Biorefinery of microalgal soluble proteins by sequential proces sing and membrane filtration, Bioresour. Technol. 225 (2017) 151-158.

[11] Y. Wu, X. Cheng, X. Zhang, Y. Xu, S. Gao, H. Zhao, L. Huo, High efficient and selective removal of $\mathrm{Pb} 2+$ through formation of lead molybdate on $\alpha-\mathrm{MoO} 3$ porous nanosheets array, J. Colloid Interface Sci. 491 (2017) 80-88.

[12] Y. Waché, A. Voilley, L. Cao-Hoang, Extraction and encapsulation of tropical natural compounds, J. Food Eng. 117 (4) (2013) 425.

[13] T.A. Arica, E. Ayas, M.Y. Arica, Magnetic MCM-41 silica particles grafted with poly (glycidylmethacrylate) brush: modification and application for removal of direct dyes, Microporous Mesoporous Mater. 243 (2017) 164-175.

[14] P.M. Budd, B.S. Ghanem, S. Makhseed, N.B. McKeown, K.J. Msayib, C.E. Tattershall, Polymers of intrinsic microporosity (PIMs): robust, solution-processable, organic nanoporous materials, Chem. Commun. 2 (2004) 230-231.

[15] P.M. Budd, K.J. Msayib, C.E. Tattershall, B.S. Ghanem, K.J. Reynolds, N.B. McKeown, D. Fritsch, Gas separation membranes from polymers of intrinsic microporosity, J. Membr. Sci. 251 (1-2) (2005) 263-269.

[16] D. Fritsch, P. Merten, K. Heinrich, M. Lazar, M. Priske, High performance organic solvent nanofiltration membranes: development and thorough testing of thin film composite membranes made of polymers of intrinsic microporosity (PIMs), J. Membr. Sci. 401-402 (2012) 222-231.

[17] W.F. Yong, F.Y. Li, Y.C. Xiao, P. Li, K.P. Pramoda, Y.W. Tong, T.S. Chung, Molecular engineering of PIM-1/Matrimid blend membranes for gas separation, J. Membr. Sci. 407-408 (2012) 47-57.

[18] J.C. Thomas, J.E. Trend, N.A. Rakow, M.S. Wendland, R.J. Poirier, D.M. Paolucci, Optical sensor for diverse organic vapors at ppm concentration ranges, Sensors (2011) 11(3)

[19] C.A. Jeffs, M.W. Smith, C.A. Stone, C.G. Bezzu, K.J. Msayib, N.B. McKeown, S.P. Perera, A polymer of intrinsic microporosity as the active binder to enhance adsorption/separation properties of composite hollow fibres, Microporous Mesoporous Mater. 170 (2013) 105-112.

[20] N.B. McKeown, P.M. Budd, Polymers of intrinsic microporosity (PIMs): organic materials for membrane separations, heterogeneous catalysis and hydrogen storage, Chem. Soc. Rev. 35 (8) (2006) 675-683.

[21] Y. Rong, A. Kolodziej, E. Madrid, M. Carta, R. Malpass-Evans, N.B. McKeown, F. Marken, Polymers of intrinsic microporosity in electrochemistry: anion uptake and transport effects in thin film electrodes and in free-standing ionic diode membranes, J. Electroanal. Chem. 779 (2016) 241-249.

[22] W.F. Yong, F.Y. Li, Y.C. Xiao, T.S. Chung, Y.W. Tong, High performance PIM-1/ matrimid hollow fiber membranes for $\mathrm{CO} 2 / \mathrm{CH} 4, \mathrm{O} 2 / \mathrm{N} 2$ and $\mathrm{CO} 2 / \mathrm{N} 2$ separation, J. Membr. Sci. 443 (2013) 156-169.

[23] S.H. Pang, M.L. Jue, J. Leisen, C.W. Jones, R.P. Lively, PIM-1 as a solution-processable "molecular basket" for $\mathrm{CO}_{2}$ capture from dilute sources, ACS Macro Lett. 4 (12) (2015) 1415-1419.

[24] S. Ramakrishna, K. Fujihara, W.-E. Teo, T.-C. Lim, Z. Ma, An Introduction to Electrospinning and Nanofibers, World Scientific, 2005.

[25] J.H. Wendorff, S. Agarwal, A. Greiner, Electrospinning: Materials, Processing, and Applications, John Wiley \& Sons, 2012.

[26] T. Uyar, E. Kny, Electrospun Materials for Tissue Engineering and Biomedical Applications: Research, Design and Commercialization, Elsevier, Woodhead Publishing, 2017.

[27] N. Bhardwaj, S.C. Kundu, Electrospinning: a fascinating fiber fabrication technique, Biotechnol. Adv. 28 (3) (2010) 325-347.

[28] F. Kayaci, C. Ozgit-Akgun, N. Biyikli, T. Uyar, Surface-decorated ZnO nanoparticles and $\mathrm{ZnO}$ nanocoating on electrospun polymeric nanofibers by atomic layer deposition for flexible photocatalytic nanofibrous membranes, RSC Adv. 3 (19) (2013) 6817-6820.

[29] A. Celebioglu, F. Kayaci-Senirmak, S. Ipek, E. Durgun, T. Uyar, Polymer-free nanofibers from vanillin/cyclodextrin inclusion complexes: high thermal stability, enhanced solubility and antioxidant property, Food Funct. 7 (7) (2016) 3141-3153.

[30] A. Senthamizhan, B. Balusamy, T. Uyar, Glucose sensors based on electrospun nanofibers: a review, Anal. Bioanal. Chem. 408 (5) (2016) 1285-1306.
[31] J.S. Bonso, G.D. Kalaw, J.P. Ferraris, High surface area carbon nanofibers derived from electrospun PIM-1 for energy storage applications, J. Mater. Chem. A 2 (2) (2014) 418-424.

[32] C. Zhang, P. Li, B. Cao, Electrospun polymer of intrinsic microporosity fibers and their use in the adsorption of contaminants from a nonaqueous system, J. Appl. Polym. Sci. 133 (22) (2016) (n/a-n/a).

[33] C. Zhang, P. Li, B. Cao, Electrospun microfibrous membranes based on PIM-1/POSS with high oil wettability for separation of oil-water mixtures and cleanup of oil soluble contaminants, Ind. Eng. Chem. Res. 54 (35) (2015) 8772-8781.

[34] E. Lasseuguette, M.-C. Ferrari, Development of microporous electrospun PIM-1 fibres, Mater. Lett. 177 (2016) 116-119.

[35] B. Satilmis, P.M. Budd, Base-catalysed hydrolysis of PIM-1: amide versus carboxylate formation, RSC Adv. 4 (94) (2014) 52189-52198.

[36] N. Du, G.P. Robertson, J. Song, I. Pinnau, M.D. Guiver, High-performance carboxylated polymers of intrinsic microporosity (PIMs) with tunable gas transport properties, Macromolecules 42 (16) (2009) 6038-6043.

[37] C.R. Mason, L. Maynard-Atem, N.M. Al-Harbi, P.M. Budd, P. Bernardo, F. Bazzarelli, G. Clarizia, J.C. Jansen, Polymer of intrinsic microporosity incorporating thioamide functionality: preparation and gas transport properties, Macromolecules 44 (16) (2011) 6471-6479.

[38] C.R. Mason, L. Maynard-Atem, K.W.J. Heard, B. Satilmis, P.M. Budd, K. Friess, M. Lanč, P. Bernardo, G. Clarizia, J.C. Jansen, Enhancement of $\mathrm{CO}_{2}$ affinity in a polymer of intrinsic microporosity by amine modification, Macromolecules 47 (3) (2014) 1021-1029.

[39] H.A. Patel, C.T. Yavuz, Noninvasive functionalization of polymers of intrinsic microporosity for enhanced $\mathrm{CO}_{2}$ capture, Chem. Commun. 48 (80) (2012) 9989-9991.

[40] B. Satilmis, M.N. Alnajrani, P.M. Budd, Hydroxyalkylaminoalkylamide PIMs: selective adsorption by ethanolamine- and diethanolamine-modified PIM-1, Macromolecules 48 (16) (2015) 5663-5669.

[41] N. Du, H.B. Park, G.P. Robertson, M.M. Dal-Cin, T. Visser, L. Scoles, M.D. Guiver, Polymer nanosieve membranes for $\mathrm{CO}_{2}$-capture applications, Nat. Mater. 10 (5) (2011) 372-375.

[42] B. Satilmis, P.M. Budd, Selective dye adsorption by chemically-modified and thermally-treated polymers of intrinsic microporosity, J. Colloid Interface Sci. 492 (2017) 81-91.

[43] C. Zhang, P. Li, W. Huang, B. Cao, Selective adsorption and separation of organic dyes in aqueous solutions by hydrolyzed PIM-1 microfibers, Chem. Eng. Res. Des. 109 (2016) 76-85.

[44] W.F. Yong, T.-S. Chung, Miscible blends of carboxylated polymers of intrinsic microporosity (cPIM-1) and matrimid, Polymer 59 (2015) 290-297.

[45] P. Salehian, W.F. Yong, T.-S. Chung, Development of high performance carboxylated PIM-1/P84 blend membranes for pervaporation dehydration of isopropanol and CO2/CH4 separation, J. Membr. Sci. 518 (2016) 110-119.

[46] K.-S. Liao, J.-Y. Lai, T.-S. Chung, Metal ion modified PIM-1 and its application for propylene/propane separation, J. Membr. Sci. 515 (2016) 36-44.

[47] H. Zhao, Q. Xie, X. Ding, J. Chen, M. Hua, X. Tan, Y. Zhang, High performance postmodified polymers of intrinsic microporosity (PIM-1) membranes based on multivalent metal ions for gas separation, J. Membr. Sci. 514 (2016) 305-312.

[48] B. Santoso, P. Yanaranop, H. Kang, I.K.H. Leung, J. Jin, A critical update on the synthesis of carboxylated polymers of intrinsic microporosity (C-PIMs), Macromolecules 50 (7) (2017) 3043-3050.

[49] M.L. Jue, C.S. McKay, B.A. McCool, M.G. Finn, R.P. Lively, Effect of nonsolvent treatments on the microstructure of PIM-1, Macromolecules 48 (16) (2015) 5780-5790.

[50] Q. Song, S. Cao, R.H. Pritchard, B. Ghalei, S.A. Al-Muhtaseb, E.M. Terentjev, A.K. Cheetham, E. Sivaniah, Controlled thermal oxidative crosslinking of polymers of intrinsic microporosity towards tunable molecular sieve membranes, Nat. Commun. 5 (2014) 4813.

[51] H. Al Kutubi, L. Rassaei, W. Olthuis, G.W. Nelson, J.S. Foord, P. Holdway, M. Carta, R. Malpass-Evans, N.B. McKeown, S.C. Tsang, et al., Polymers of intrinsic microporosity as high temperature templates for the formation of nanofibrous oxides, RSC Adv. 5 (89) (2015) 73323-73326.

[52] K. Lee, J.W. Jeon, B.M. Maeng, K.M. Huh, J. Chan Won, Y. Yoo, Y.S. Kim, B.G. Kim, Synthesis and characterization of polyethersulfone with intrinsic microporosity, RSC Adv. 6 (74) (2016) 70320-70325.

[53] A. Celebioglu, T. Uyar, Electrospun porous cellulose acetate fibers from volatile solvent mixture, Mater. Lett. 65 (14) (2011) 2291-2294.

[54] T.S. Anokhina, A.A. Yushkin, P.M. Budd, A.V. Volkov, Application of PIM-1 for solvent swing adsorption and solvent recovery by nanofiltration, Sep. Purif. Technol. 156 (Part 2) (2015) 683-690.

[55] S. Tsarkov, V. Khotimskiy, P.M. Budd, V. Volkov, J. Kukushkina, A. Volkov, Solvent nanofiltration through high permeability glassy polymers: effect of polymer and solute nature, J. Membr. Sci. 423-424 (2012) 65-72.

[56] M. Shakeel, K. Mehmood, M. Waseem, W. Rehman, K.H. Shah, M. Nawaz, Adsorption of methyl orange from aqueous solution by polymer of intrinsic microporosity: isotherms and kinetics study, J. Chem. Soc. Pak. 39 (3) (2017) 337-342.

[57] M. Rafatullah, O. Sulaiman, R. Hashim, A. Ahmad, Adsorption of methylene blue on low-cost adsorbents: a review, J. Hazard. Mater. 177 (1) (2010) 70-80. 